\title{
The Older They Are, the Less Successful They Become? Findings from the Georgia Centenarian Study
}

\author{
Jinmyoung Cho, ${ }^{1,2}$ Peter Martin, ${ }^{3}$ and Leonard W. Poon ${ }^{4}$ \\ ${ }^{1}$ Center for Applied Health Research, Scott and White Healthcare, Temple, TX 76508, USA \\ ${ }^{2}$ School of Rural Public Health, Texas A $\checkmark M$ Health Science Center, College Station, TX 77845, USA \\ ${ }^{3}$ Human Development and Family Studies, Iowa State University, Ames, IA 50011, USA \\ ${ }^{4}$ Institute of Gerontology, University of Georgia, Athens, GA 30602, USA \\ Correspondence should be addressed to Jinmyoung Cho, chojm85@gmail.com
}

Received 5 April 2012; Revised 23 May 2012; Accepted 31 May 2012

Academic Editor: Hiroshi Nose

Copyright ( $) 2012$ Jinmyoung Cho et al. This is an open access article distributed under the Creative Commons Attribution License, which permits unrestricted use, distribution, and reproduction in any medium, provided the original work is properly cited.

\begin{abstract}
This study examined whether oldest-old adults are successful agers. Three hundred and six octogenarians and centenarians of Phase III of the Georgia Centenarian Study participated in this study. A first model examined Rowe and Kahn's successful aging model (Rowe and Khan (1997 and 1998)) including the probability of disease, physical or cognitive capacity, and engagement with life. All three components were applied to assess how many oldest-old adults satisfied all three criteria. The result showed about $15 \%$ of octogenarians $(15.1 \%)$, and none of centenarians satisfied all three components of successful aging. Consequently, a second alternative model focused on psychosocial aspects including three different components: subjective health, perceived economic status, and happiness. Different from Rowe and Kahn's successful aging model, a total of $62.3 \%$ of octogenarians and $47.5 \%$ of centenarians satisfied all three components of the alternative model of successful aging. The results suggest that additional criteria of successful aging should be considered thereby expanding the concepts and multidimensional aspects of successful aging among oldest-old adults.
\end{abstract}

\section{Introduction}

There is an oriental word- "bullojangsaeng"-which means physical immortality or external life in several Asian countries (e.g., Korea). The desire to live longer and healthy has been an aspiration of humankind for all ages and in all countries. The advancement of science has resulted in lower mortality. A consequence of lower mortality in the United States from 17.2 to 8.2 per 1,000 population and increases in life expectancy from 47 years in 1900 to 74 for men and 79 years for women [1] is that most people in the United States can expect to live longer. As the population of centenarians, another important segment of the older population, is expected to grow from 37,000 in 1990 to 850,000 in 2050 [2], it is important for oldest-old adults to understand successful aging when compared to relatively younger old adults. Even though increased longevity has been achieved, it is not clear whether increasing longevity is directly connected with successful aging.
Since Rowe and Kahn $[3,4]$ proposed three indicators for successful aging (i.e., low probability of disease and diseaserelated disability, high cognitive and physical functional capacity, and active engagement with life), a number of studies have conceptualized successful aging indicators and examined older adults as successful agers based on the three criteria. However, many older adults have rarely satisfied these criteria because of the presence of disabilities and chronic diseases [5-8]. Moreover, oldest-old adults may easily fail to be categorized as successful agers when these criteria are applied. Kahn admitted that successful aging models should be complementary with other models [9], and successful aging model should encompass the criteria especially for oldest-old adults. For example, subjective health has been significantly correlated with functioning and mortality among oldest-old adults [10-14]. As subjective health has been generally viewed as a comprehensive single indicator of successful aging $[15,16]$, it is included as an 
alternative criterion instead of the physical health component of successful aging models in this study.

Several critical viewpoints of Rowe and Kahn's model have also suggested alternative indicators for successful aging models. George [17], for example, argued that the components of successful aging primarily focus on physical aspects and addressed an important question: "Is an older adult successfully aging if he/she is disability-free, physically and cognitive intact, and generally active, but rates the quality of life as poor or not good?" [17, page 322]. Although the majority of successful aging studies have included physical aspect as an essential factor for successful aging, psychological factors including emotional well-being have been identified as significant factors, especially in studies including very old adults $[18,19]$. Thus, happiness, as a construct of life satisfaction or quality of life, in this study included "achievement of successful adaptation and expert survivorship in aging" ([13, page 3$]$ and [20]).

Furthermore, Rowe and Kahn [3, 4] overlooked important aspects of aging such as financial resources, which directly or indirectly influence later life such as access to attain services for basic needs, physical health, living arrangement, and quality of life [21-25]. Since many oldest-old adults rely on family members' assistance, Social Security benefits, and the Medicaid program [26], perception or satisfaction of economic status may explain overall quality of life among older adults instead of objective income measures $[27,28]$.

The purpose of this study is to investigate Rowe and Kahn's $[3,4]$ "successful aging" model using data from the Georgia Centenarian Study. The overall objectives are to explore whether oldest-old adults are successful agers or not, to explore whether oldest-old adults are satisfied based on the criteria of successful aging, and to expand the psychological concept of successful aging among oldest-old adults. The following research questions are examined.

(1) Will oldest-old adults satisfy the components of successful aging (i.e., physical health, cognitive/physical functioning, and engagement with life)?

(2) Based on previous research, will oldest-old adults satisfy alternative criteria of successful aging (i.e., subjective health, financial resources, and happiness)?

\section{Methods}

2.1. Participants. As discussed in our previous work [29], the sampling frame of the Georgia Centenarian Study (GCS, Phase III) [30], which provides data for this study, had two components. The first one was to identify the proportion of all residents of skilled nursing facilities (SNFs) and personal care homes (PCHs) in a 44-county area in northern Georgia. Based on census proportions, the project recruited residents of SNFs and PCHs as well as communitydwelling residents. A second recruiting strategy was to use date-of-birth information in voter registration files. Based on these two components and five different characteristics (geographic, age, gender, ethnicity, and type of residence) a sample of octogenarians and centenarians was drawn for this study [30]. Information was collected through four sequential sessions, and information regarding resources and adaptation of older adults was the focus of this study.

Among 375 octogenarians and centenarians, three hundred and six participants (72 octogenarians and 234 centenarians) were left due to missing data and several proxies who had marginal mental status scores (proxy's MMSE < 23 ). The majority of octogenarians $(69.4 \%)$ and centenarians $(82.5 \%)$ were female. Over two-thirds of octogenarians $(86.6 \%)$ lived in their own homes, whereas less than half of the centenarians $(45.5 \%)$ lived in their own homes. As expected, most participants were widowed (centenarians: $86.3 \%$ and octogenarians: $53.7 \%$ ). More octogenarians had an education beyond a high school degree than centenarians (octogenarians: $59.6 \%$ and centenarians: $40.4 \%$ ). More octogenarians $(86.1 \%)$ had high levels (MMSE $\geq 23$ ) of cognition status functioning than centenarians (32.7\%). In addition, in terms of the excluded 69 participants' information, they had similar characteristics when compared with samples used in this study. Most of them were female (73.9\%), Caucasians $(78.3 \%)$, widowed $(77.9 \%)$, and over half of them $(52.2 \%)$ lived in private home/apartments. There was no significant difference between the excluded and the remaining sample in mental status. A summary of demographic characteristics of the remaining sample of 306 can be found in Table 1 .

\subsection{Measures of Rowe and Kahn's Successful Aging Model.} The criteria suggested by Rowe and Kahn $[3,4]$ were applied to oldest-old adults and included low probability of disease, physical or cognitive capacity, and engagement with life. Even though there is little agreement about the operationalization and definition of successful aging nor its measurement [31-34], each definition will follow the most often used operationalization as reviewed by Depp and Jeste [16]. Furthermore, the data used in this study were collected from proxy informants. It is not always easy nor feasible to obtain information from oldest-old adults. Many studies have shown a significant relationship between self and proxies or between self and physicians' reports [35] and that there was no potential bias such as disagreements between proxies and participants [36-40] or mean differences on mental health ratings between proxies and participants [41]. Therefore, we included data from proxy informants for several measures in this study.

2.2.1. Low Probability of Disease. Rowe and Kahn [3, 4] defined "probability of disease" not only as the absence or presence of disease itself but also the absence, presence, or severity of risk factors for disease. Following this definition and based on Strawbridge et al. [8], absence of congestive heart failure, cancer, high blood pressure, Parkinson's disease, chronic pulmonary disease, and diabetes mellitus was used for low probability of disease. The reports were used based on centenarians' reports, proxy reports, medical reports, care facility's reports, or other available resources for best available information. 
TABLE 1: Summary of semographic characteristics.

\begin{tabular}{|c|c|c|c|c|c|}
\hline \multirow{2}{*}{ Demographic characteristics } & \multicolumn{2}{|c|}{ Octogenarians $(n=72)$} & \multicolumn{2}{|c|}{ Centenarians $(n=234)$} & \multirow{2}{*}{$\chi^{2}$} \\
\hline & $n$ & $\%$ & $n$ & $\%$ & \\
\hline Gender & & & & & $5.72 *$ \\
\hline Female & 50 & 69.4 & 193 & 82.5 & \\
\hline Male & 22 & 30.6 & 41 & 17.5 & \\
\hline Type of residence & & & & & $35.52 * * *$ \\
\hline Private home/Apartment & 58 & 86.6 & 97 & 45.5 & \\
\hline Personal care (Assisted Living) & 1 & 1.5 & 41 & 19.2 & \\
\hline Nursing home & 8 & 11.9 & 75 & 35.2 & \\
\hline Ethnicity & & & & & 2.02 \\
\hline White/Caucasian & 61 & 84.7 & 179 & 76.5 & \\
\hline Black/African American & 11 & 15.3 & 55 & 23.5 & \\
\hline Education & & & & & $22.58^{* *}$ \\
\hline $0-4$ years & 1 & 1.5 & 11 & 4.9 & \\
\hline $5-8$ years & 2 & 3.0 & 53 & 23.8 & \\
\hline Some high school & 6 & 9.0 & 26 & 11.7 & \\
\hline High school diploma & 18 & 26.9 & 43 & 19.3 & \\
\hline Trade school or vocational degree & 8 & 11.9 & 28 & 12.6 & \\
\hline Some college & 9 & 13.4 & 22 & 9.9 & \\
\hline College degree & 13 & 19.4 & 19 & 8.5 & \\
\hline Graduate degree & 10 & 14.9 & 21 & 9.4 & \\
\hline Marital status & & & & & $54.15^{* * *}$ \\
\hline Never married & 1 & 1.5 & 9 & 4.3 & \\
\hline Married & 26 & 38.8 & 10 & 4.7 & \\
\hline Widowed & 36 & 53.7 & 182 & 86.3 & \\
\hline Divorced & 4 & 6.0 & 9 & 4.3 & \\
\hline Separated & 0 & 0.0 & 1 & 0.5 & \\
\hline Cognitive status & & & & & $63.59 * * *$ \\
\hline Low $(\mathrm{MMSE} \leq 17)$ & 9 & 12.5 & 112 & 48.3 & \\
\hline $\operatorname{Mid}(18 \leq \mathrm{MMSE} \leq 22)$ & 1 & 1.4 & 44 & 19.0 & \\
\hline High (MMSE $\geq 23$ ) & 62 & 86.1 & 76 & 32.7 & \\
\hline
\end{tabular}

${ }^{*} P<0.05$. ${ }^{* *} P<0.01$. ${ }^{* * *} P<0.001$.

2.2.2. High Cognitive/Physical Capacity. As the second component of successful aging, physical/cognitive capacity was defined as potential for activities $[3,4]$. Physical capacity was examined with instrumental activities of daily living (IADLs; seven items), and physical activities of daily living (PADLs; seven items) comprise the self-care capacity assessment [42] with coefficient $\alpha=.92$ and $\alpha=.88$, respectively. In addition, internal consistency of all 14 items was $\alpha=0.94$. All 14 items were scaled so that 2 = without help (e.g., can clean floors, etc.); 1 = with some help (e.g., can prepare some things but unable to cook full meals yourself); or $0=$ completely unable to prepare any meals. Those who had no help with PADL were coded as high physical capacity $(=1)$, and the remains were coded as low physical capacity $(=0)$ [43]. Cognitive capacity was examined with the Mini-Mental Status Examination (MMSE) [44]. The MMSE is commonly used for evaluation of cognitive impairment. The MMSE is composed of five sections: orientation, registration, attention and calculation, recall, and language. The reliability is 0.98 for older adults, and concurrent validity with the Wechsler
Adult Intelligence Scale was 0.78 in the original study [44]. The performance ranged from 0 to 30 , and the thirty items yielded a reliability of $\alpha=0.87$ for this study. MMSE scores of 23 or higher were coded as high cognitive capacity $(=1)$, and the remaining scores were coded as low cognitive capacity $(=0)$ [45]. Taking high physical capacity and high cognitive capacity together was used as the second definition of Rowe and Kahn's model in this study [19].

2.2.3. Active Engagement with Life. Engagement with life, the final component of successful aging, was defined as interpersonal relations and productive activities [3, 4]. Active engagement with life was examined with two constructs, interpersonal relations and productive activity. For interpersonal relations, two questions of social support developed by Fillenbaum [42] were used: "How many people do you know well enough to visit with in his/her home or in their homes?" and "About how many times did you talk to someonefriends, relatives, or others on the telephone in the past 
week?" Those who had been spending time with family and/or friends at least once a week and having three or more people to visit were coded as active interpersonal relations $(=1)$, and the remaining were coded as inactive relations $(=0)$ [6]. For productive activity, experience of volunteer work was coded as " 1 " and the remaining were coded as " 0 " [46]. Both interpersonal relations and productive activity were considered together.

2.3. Measures of Alternative Successful Aging Model. The criteria for alternative successful aging model follow the most frequently used operationalization as reviewed by Depp and Jeste [16] as well.

2.3.1. Subjective Health. Subjective health was used as a criterion instead of low probability of disease. Health status rated as either "good" or "excellent" was coded as good health (= $1)$ and "fair" or "poor" was coded as poor health $(=0)[47]$.

2.3.2. Perceived Economic Status. Perceived economic status, which was neglected by Rowe and Kahn [3, 4], was included. Perceived economic status was measured with three items: the capacity to meet emergencies, to take care of needs, and to buy small luxuries [42]. Among the three items, those who were able to meet emergencies, to buy small luxuries, and to take care of needs fairly or very well were coded as better economic status $(=1)$, and the remaining were coded as poor status $(=0)$.

2.3.3. Happiness. The last indicator for successful aging included psychological aspects in later life, happiness. The top third of the summary scores of three items ("I am just as happy now as when I was younger," "My life could be happier than it is now" (reversed), "These are the best years of my life") was used for happiness [19]. Those who had scores 1 to 3 on the summary scores of the three items were coded as happy $(=1)$, and those who had scored -3 to 0 on the summary scores of the three items were coded as unhappy $(=0)$.

2.4. Data Analysis. Pearson's Chi-squared tests were performed to identify study participants to achieve the criteria of original successful aging model and the alternative successful aging model. Data were analyzed using the SPSS Statistical Software Package (version 19.0; SPSS).

\section{Results}

The results are separated into two sections. First, Rowe and Kahn's successful aging model was examined with octogenarians and centenarians. Three components were investigated separately and aggregately by age groups. Second, an alternative successful aging model with three criteria (i.e., subjective health, perceived economic status, and happiness) was analyzed in the same manner as in the first section.

3.1. Oldest-Old Adults and Rowe and Kahn's Successful Aging Model. Each component was applied to octogenarians and
TABLE 2: Proportion of successful aging criteria.

\begin{tabular}{lccc}
\hline & Octogenarians & Centenarians & $\chi^{2}$ \\
\hline $\begin{array}{l}\text { Low probability of } \\
\text { disease }\end{array}$ & $28.8 \%$ & $29.5 \%$ & .01 \\
$\begin{array}{l}\text { High physical and } \\
\text { cognitive capacity }\end{array}$ & $58.0 \%$ & $4.4 \%$ & $107.67^{* * *}$ \\
$\begin{array}{l}\text { Active engagement } \\
\text { with life }\end{array}$ & $63.5 \%$ & $57.5 \%$ & .72 \\
${ }^{* * *} P<0.001$. & & &
\end{tabular}

centenarians, and how many octogenarians and centenarians satisfied each component was investigated. For "low probability of disease," $28.8 \%$ of octogenarians and $29.5 \%$ of centenarians satisfied this criterion. Over half of octogenarians (58\%) and $4.4 \%$ of centenarians satisfied the physical and cognitive capacity criteria. There was a significant difference in association between age and physical/cognitive capacity among octogenarians and centenarians, $\chi^{2}(1, N=295)=$ 107.67, $P<0.001$. For engagement with life, $63.5 \%$ of octogenarians and $57.5 \%$ of centenarians met the third criterion (Table 2). Therefore, we can argue that physical and cognitive capacities are critical factors distinguishing octogenarians and centenarians.

Next, all three components were applied to investigate how many octogenarians and centenarians satisfied all criteria. Figure 1 shows the combined proportion of participants, octogenarians, and centenarians, who satisfied three components of successful aging. Over 15\% of octogenarians $(15.1 \%)$ and none of centenarians satisfied all three components of successful aging. In addition, $15.1 \%$ of octogenarians and $27.3 \%$ of centenarians did not achieve any of the three components of successful aging. One-third (34\%) of octogenarians and $18 \%$ of centenarians met two of the three components. Over one-third of octogenarians (35.9\%) and $54.6 \%$ of the centenarians achieved only one component of successful aging. Specifically, it might be worthy to note that although centenarians had a high probability of disease and lower potential capacities, $39.1 \%$ of them had a high level of life engagement. Therefore, based on Rowe and Kahn's $[3,4]$ criteria of low probability of disease, high physical and cognitive capacity, and engaged lifestyle, we could argue that living longer does not necessarily imply successful aging.

3.2. Oldest-Old Adults and Alternative Successful Aging Model. However, are these three criteria the only viable aspects of successful aging among oldest-old adults? The three criteria have been commonly used to examine successful aging but, as Kahn [9] suggested, the successful aging model should be complemented with other models. Hence, it might also be necessary to expand the definition of successful aging. An alternative model for successful aging with three criteria (i.e., subjective health, perceived economic status, and happiness) is explored in this section.

Each component was applied to octogenarians and centenarians, and how many octogenarians and centenarians were satisfied with each component was investigated. For "subjective health," $77.5 \%$ of octogenarians and $73.0 \%$ of 

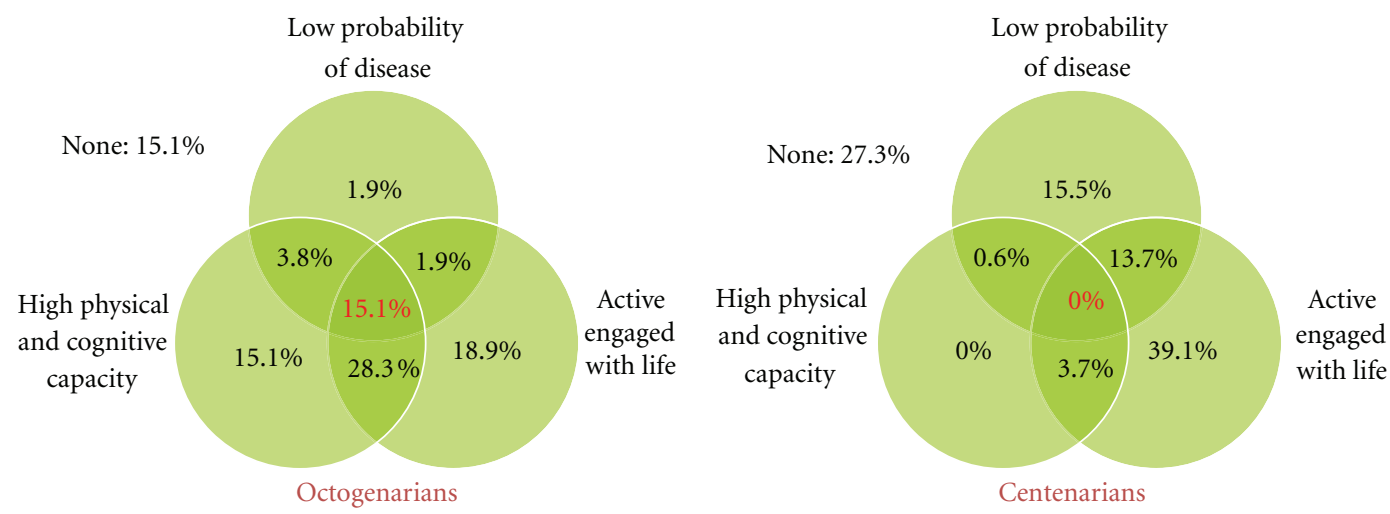

FIGURE 1: Drawings of age group comparisons for original successful aging model between octogenarians and centenarians. Numbers represent the proportion of each age group satisfied with components of the successful aging model.
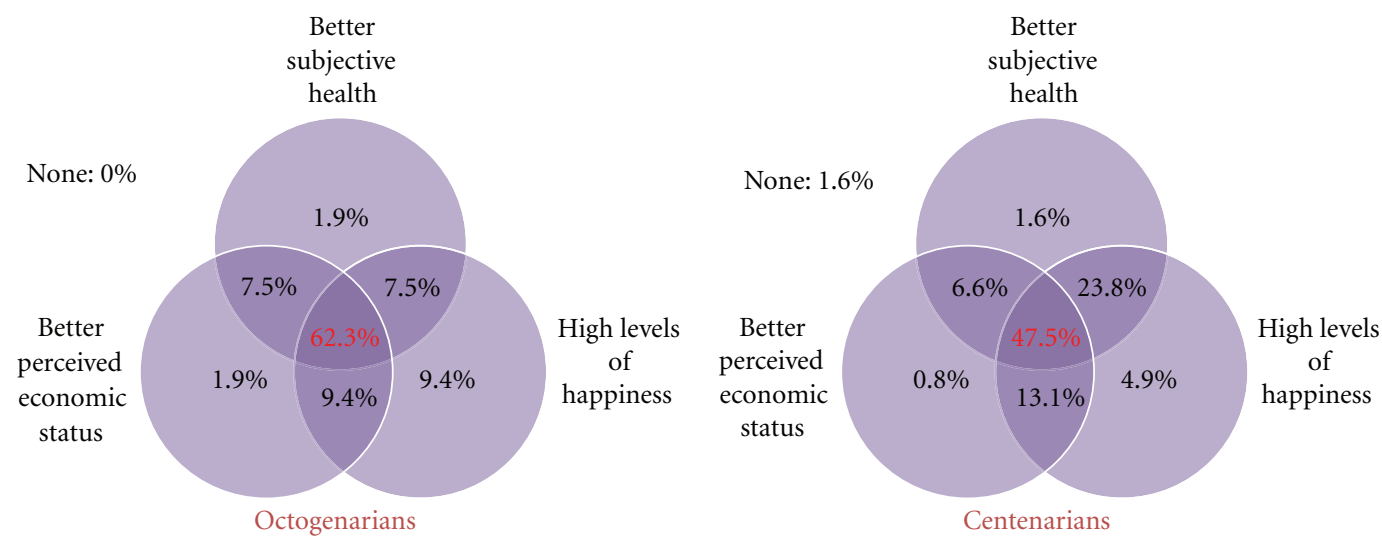

FIGURE 2: Drawings of age group comparisons for alternative successful aging model between octogenarians and centenarians. Numbers represent the proportion of each age group satisfied with components of the alternative successful aging model.

TABLE 3: Proportion of alternative successful aging criteria.

\begin{tabular}{lccc}
\hline & Octogenarians & Centenarians & $\chi^{2}$ \\
\hline Better subjective health & $77.5 \%$ & $73.0 \%$ & .57 \\
Better perceived & $78.8 \%$ & $61.8 \%$ & $6.49^{*}$ \\
economic status & $89.8 \%$ & $89.7 \%$ & .00 \\
\hline High level of happiness & & &
\end{tabular}

${ }^{*} P<0.05$.

centenarians satisfied this criterion. Over three quarters of octogenarians $(78.8 \%)$ and $61.8 \%$ of centenarians satisfied the perceived economic status criterion. There was a significant difference in association between age and perceived economic status among octogenarians and centenarians, $\chi^{2}(1, N=286)=6.49, P<0.05$. This indicates a larger proportion of octogenarians satisfied the perceived economic status criterion compared to centenarians. For happiness, $89.8 \%$ of octogenarians and $89.7 \%$ of centenarians met the third criterion (Table 3 ). Therefore, compared to Rowe and Kahn's $[3,4]$ criteria, more oldest-old adults satisfied these alternative aspects of successful aging criteria.

As was done with Rowe and Kahn's [3, 4] successful aging criteria, all three components for the alternative model were applied to investigate how many octogenarians and centenarians satisfied all criteria. Figure 2 shows the combined proportion of participants, octogenarians and centenarians, who satisfied the three components of successful aging. A total of $62.3 \%$ of octogenarians and $47.5 \%$ of centenarians satisfied all three components of the alternative model of successful aging. Less than $25 \%$ of octogenarians (24.4\%) and less than half of centenarians $(43.5 \%)$ met two of the three components. Over 10\% of octogenarians (13.2\%) and $7.3 \%$ of centenarians achieved only one component of successful aging. In addition, no octogenarian and only $1.6 \%$ of centenarians did not achieve any of the three components of the alternative successful aging model.

\section{Discussion}

Rowe and Kahn's successful aging model was applied to oldest-old adults in this study. The components of the successful aging model included low probability of disease, high cognitive/physical functional capacity, and active engagement in life. The first research question was whether oldest-old adults would satisfy all three components of the successful aging model. Only $15.1 \%$ of octogenarians and none of the centenarians satisfied all three components. 
There is one obvious reason why oldest-old adults did not maintain all three components of the successful aging model. The participants used in the Rowe and Kahn study were 70 to 79 years old $[3,4]$. The participants in this study were over 80 years of age, and most of them were centenarians. Physical health, which is a critical factor in Rowe and Kahn's aging model defined as the absence of disease and disability, shows dramatic decline after the age of 80 [48]. This might be the primary reason that our participants, especially centenarians, did not satisfy the criteria of Rowe and Kahn's successful aging model.

Because this research question was not supportive of Rowe and Kahn's model with oldest-old adults, an alternative successful aging model was suggested (Research Question 2). The reason to suggest an alternative successful aging model is that successful aging should not be limited to a few concepts and variables. Kahn [9] agreed that the successful aging model should be complemented by other models or have a broader definition to adjust for the limitation that only a significant number of people could reach advanced age free of age-associated disease and without appreciable functional deterioration [8]. Consistent with other centenarian studies, this study confirmed the fact that it is naturally difficult, if not impossible, to reach advanced age free of diseases and disability [49-52].

The alternative successful aging model provided us with a different picture of successful aging for advanced old age. Instead of low probability of disease, high cognitive/physical functional capacity, and active engagement in life, subjective health, perceived economic status, and happiness were included. The results showed that $62.3 \%$ of octogenarians and $47.5 \%$ of centenarians met the criteria of the alternative successful aging model. Perhaps the results can best be interpreted with the compensatory mechanism or resilience. In other words, although physiological change or functional deterioration is closely associated with increasing age, psychological and social aspects of aging may not have positive relationships with physiological changes across the life span [52]. Therefore, certain psychological or social mechanisms such as happiness, positive affect, and social ties may compensate for physiological decline and allow some older adults to age successfully [52]. Thus, this alternative aspect of the successful aging model may contribute to the multidimensional successful aging construct and help older adults achieve successful aging even under conditions of physical health limitations and disabilities.

Even though this study provides an innovative perspective on successful aging, it is important for researchers to pay attention to a couple of limitations. First, the sample of this study was from only one geographic area of the United States. Other oldest-old adults in different regions might present different patterns of successful aging. In addition, there were some discrepancies between the proportions of sex and race in this study and national statistics. The 2010 census data, for instance, indicated that there were $36.3 \%$ male and $63.7 \%$ female people among the population of 80 years old and older [53], whereas our data included $79.4 \%$ of women and $20.6 \%$ men. Homogeneity may have limited the interpretation and application of these results to larger populations of oldest-old adults across the country. Second, we should consider different time points to assess whether oldest-old adults are successful agers or not. In other words, we need to consider survivorship effects when interpreting the results. Baltes and Smith [54] suggested that studies focusing on very old age pay attention to survival and mortality $[55,56]$. For example, we can assume that survivors into very late life at some point in their lives had better scores in some domains such as health, intelligence, education, and psychological aspects than their counterparts who died prematurely or were close to death when being assessed [54]. Therefore, even though none of the centenarians satisfied the criteria of the successful aging model compared to $15.1 \%$ of octogenarians, centenarians might have at some point in their lives been functioning better on the three criteria of successful aging than those who had died earlier. Thus, we should differentiate age differences from selective survivorship in terms of considering longevity and successful aging. Finally, it is noted that the original successful aging model used objective measures, but alternative criteria of this study were not objective measures. A number of studies have shown discrepancies between self-rated-successful-agers and successful-agers-based Rowe and Kahn's criteria (e.g., [8, 57]). However, as Kahn [9] suggested, the purpose of this study was to contribute diverse aspects to a successful aging model among oldest-old adults rather than comparing two equivalent models.

Despite these limitations, this study revealed interesting insight into the successful aging model of oldest-old adults. This information has numerous implications for gerontologists and practitioners. In particular, this investigation suggests that the successful aging model may not apply to oldestold adults. Researchers and practitioners should consider many different factors for successful aging. Future research on oldest-old adults should use sequential designs when assessing successful aging. For example, investigators may want to apply the successful aging model to different cohort groups for several years. Based on this sequential design, the investigators may be able to explore the simultaneous examination of time and age effects for successful aging.

It may be difficult to achieve successful aging in extremely late life. There is still no agreement on the definition of successful aging, and future work needs to expand the criteria for successful aging. In addition, more work needs to be done to examine predictors of successful aging as parts of developmental processes. Future work will contribute to the study of successful aging and help older adults achieve successful aging for as long as possible with a systematic approach to consider the past and present life and with a holistic view to understand age-related changes and challenges.

\section{Acknowledgments}

Additional authors included S. M. Jazwinski, R. C. Green, M. MacDonald, M. Gearing, M. A. Johnson, J. L. Woodard, J. S. Tenover, I. C. Siegler, W. L. Rodgers, D. Hausman, J. Arnold, and A. Davey. The Georgia Centenarian Study (Leonard W. Poon, PI) was funded by 1P01-AG17553 from the National 
Institute on Aging, a collaboration among The University of Georgia, Tulane University Health Sciences Center, Boston University, University of Kentucky, Emory University, Duke University, Wayne State University, Iowa State University, Temple University, and University of Michigan. Authors acknowledge the valuable recruitment and data acquisition effort from M. Burgess, K. Grier, E. Jackson, E. McCarthy, K. Shaw, L. Strong, and S. Reynolds, data acquisition team manager; S. Anderson, E. Cassidy, M. Janke, and J. Savla, data management; M. Poon for project fiscal management. Special thanks to Christine C. Cook, Jennifer Margrett, Daniel W. Russell, and Mack Shelly for their comments on an earlier draft of this paper.

\section{References}

[1] Centers for Disease Control and Prevention [CDC], "The state of aging and health in America 2004," http://www.agingsociety .org/agingsociety/pdf/SAHA_2004.pdf.

[2] U. S. Bureau of the Census, "65+ in the United States: 2005," Current Population Report, P23, 209, Government Printing Office, Washington, DC, USA, 2005.

[3] J. W. Rowe and R. L. Kahn, "Successful aging," Gerontologist, vol. 37, no. 4, pp. 433-440, 1997.

[4] J. W. Rowe and and R. L. Kahn, Successful Aging, Pantheon Books, New York, NY, USA, 1998.

[5] M. Minkler and and P. Fadem, "Successful aging: a disability perspective," Journal of Disability Policy Studies, vol. 12, no. 4, pp. 229-235, 2002.

[6] L. P. Montross, C. Depp, J. Daly et al., "Correlates of self-rated successful aging among community-dwelling older adults," American Journal of Geriatric Psychiatry, vol. 14, no. 1, pp. 43 51, 2006.

[7] J. Reichstadt, C. A. Depp, L. A. Palinkas, D. P. Folsom, and D. V. Jeste, "Building blocks of successful aging: a focus group study of older adults perceived contributors to successful aging," American Journal of Geriatric Psychiatry, vol. 15, no. 3, pp. 194-201, 2007.

[8] W. J. Strawbridge, M. I. Wallhagen, and R. D. Cohen, "Successful aging and well-being: self-rated compared with Rowe and Kahn," Gerontologist, vol. 42, no. 6, pp. 727-733, 2002.

[9] R. L. Kahn, "On "successful aging and well-being: self-rated compared with Rowe and Kahn," Gerontologist, vol. 42, no. 6, pp. 725-726, 2002.

[10] E. L. Idler and Y. Benyamini, "Self-rated health and mortality: a review of twenty-seven community studies," Journal of Health and Social Behavior, vol. 38, no. 1, pp. 21-37, 1997.

[11] Y. Lee, "The predictive value of self assessed general, physical, and mental health on functional decline and mortality in older adults," Journal of Epidemiology and Community Health, vol. 54, no. 2, pp. 123-129, 2000.

[12] G. Liu and Z. Zhang, "Sociodemographic differentials of the self-rated health of the oldest-old Chinese," Population Research and Policy Review, vol. 23, no. 2, pp. 117-133, 2004.

[13] L. W. Poon, P. Martin, A. Bishop et al., "Understanding centenarians' psychosocial dynamics and their contributions to health and quality of life," Current Gerontology and Geriatrics Research, vol. 2010, Article ID 680657, 13 pages, 2010.

[14] M. E. Quinn, M. A. Johnson, L. W. Poon, and P. Martin, "Psychosocial correlates of subjective health in sexagenarians, octogenarians, and centenarians," Issues in Mental Health Nursing, vol. 20, no. 2, pp. 151-171, 1999.
[15] A. I. Berg, L. Hoffman, L. B. Hassing, G. E. McClearn, and B. Johansson, "What matters, and what matters most, for change in life satisfaction in the oldest-old? A study over 6 years among individuals 80+," Aging and Mental Health, vol. 13, no. 2, pp. 191-201, 2009.

[16] C. A. Depp and D. V. Jeste, "Definitions and predictors of successful aging: a comprehensive review of larger quantitative studies," American Journal of Geriatric Psychiatry, vol. 14, no. 1, pp. 6-20, 2006.

[17] L. K. George, "Perceived quality of life," in Handbook of Aging and the Social Science, R. H. Binstock and and L. K. George, Eds., pp. 320-336, Academic Press, San Diego, Calif, USA, 2006.

[18] T. Knight and L. A. Ricciardelli, "Successful aging: perceptions of adults aged between 70 and 101 years," International Journal of Aging and Human Development, vol. 56, no. 3, pp. 223-245, 2003.

[19] M. Von Faber, A. Bootsma-Van Der Wiel, E. Van Exel et al., "Successful aging in the oldest old," Archives of Internal Medicine, vol. 161, no. 22, pp. 2694-2700, 2001.

[20] S. Hill and and D. M. Buss, "Evolution and subjective wellbeing," in inScience of Subjective Well-Being, M. Eid and and R. J. Larsen, Eds., pp. 62-79, Guilford Press, New York, NY, USA, 2008.

[21] S. Crystal and D. Shea, "The economic well-being of the elderly," Review of Income and Wealth, vol. 36, no. 3, pp. 227247, 1990.

[22] M. Pinquart and S. Sörensen, "Influences of socioeconomic status, social network, and competence on subjective wellbeing in later life: a meta-analysis," Psychology and Aging, vol. 15, no. 2, pp. 187-224, 2000.

[23] L. R. Slivinske, V. L. Fitch, and D. P. Morawski, "The wellness index: developing an instrument to assess elders' well-being," Journal of Gerontological Social Work, vol. 25, pp. 185-204, 1996.

[24] W. D. Spector, "Cognitive impairment and disruptive behaviors among community-based elderly persons: implications for targeting long-term care," Gerontologist, vol. 31, no. 1, pp. $51-59,1991$.

[25] R. I. Stone and C. M. Murtaugh, "The elderly population with chronic functional disability: implications for home care eligibility," Gerontologist, vol. 30, no. 4, pp. 491-496, 1990.

[26] M. A. Goetting, P. Martin, L. W. Poon, and M. A. Johnson, "The economic well-being of community-dwelling centenarians," Journal of Aging Studies, vol. 10, no. 1, pp. 43-55, 1996.

[27] E. Diener, E. Sandvik, L. Seidlitz, and M. Diener, "The relationship between income and subjective well-being: relative or absolute?" Social Indicators Research, vol. 28, no. 3, pp. 195223, 1993.

[28] H. C. Hsu, "Trajectory of life satisfaction and its relationship with subjective economic status and successful aging," Social Indicators Research, vol. 99, no. 3, pp. 455-468, 2010.

[29] J. Cho, P. Martin, M. MacDonald, J. Margrett, and L. W. Poon, "The relationship between health and psychological wellbeing among oldest-old adults," Journal of Aging Research, vol. 2011, Article ID 605041, 8 pages, 2011.

[30] L. W. Poon, S. M. Jazwinski, R. C. Green et al., "Methodological considerations in studying centenarians: lessons learned from the Georgia Centenarian Studies," in Annual Review of Gerontology and Geriatrics:, L. W. Poon and T. T. Perls, Eds., vol. 27 of Biopsychosocial Approaches to Longevity, pp. 231264, Springer, New York, NY, USA, 2007. 
[31] A. Bowling, "Aspirations for older age in the 21st century: what is successful aging?" International Journal of Aging and Human Development, vol. 64, no. 3, pp. 263-297, 2007.

[32] D. V. Jeste, "Feeling fine at a hundred and three: secrets of successful aging," American Journal of Preventive Medicine, vol. 28, no. 3, pp. 323-324, 2005.

[33] S. J. Lupien and N. Wan, "Successful ageing: from cell to self," Philosophical Transactions of the Royal Society B, vol. 359, no. 1449, pp. 1413-1426, 2004.

[34] E. A. Phelan and E. B. Larson, "'Successful aging'-where next?" Journal of the American Geriatrics Society, vol. 50, no. 7, pp. 1306-1308, 2002.

[35] S. S. Bassett, J. Magaziner, and J. R. Hebel, "Reliability of proxy response on mental health indices for aged, communitydwelling women," Psychology and Aging, vol. 5, no. 1, pp. 127$132,1990$.

[36] D. Gu, "General data quality assessment of the Chinese Longitudinal Healthy Longevity Survey," in Healthy Longevity in China: Demographic, Socioeconomic, and Psychological Dimensions, Y. Zeng, D. Poston, D. A. Vlosky, and D. Gu, Eds., pp. 39-59, Springer, New York, NY, USA, 2008.

[37] R. L. Kane, R. A. Kane, B. Bershadsky et al., "Proxy sources for information on nursing home residents' quality of life," Journals of Gerontology, vol. 60, no. 6, pp. S318-S325, 2005.

[38] W. L. Rodgers and A. R. Herzog, "Collecting data about the oldest: problems and procedures," in The Oldest Old, R. M. Suzman, D. P. Willis, and K. G. Manton, Eds., pp. 135-156, Oxford University Press, New York, NY, USA, 1992.

[39] H. Tamim, J. McCusker, and N. Dendukuri, "Proxy reporting of quality of life using the EQ-5D," Medical Care, vol. 40, no. 12, pp. 1186-1195, 2002.

[40] M. Weinberger, G. P. Samsa, K. Schmader, S. M. Greenberg, D. B. Carr, and D. S. Wildman, "Comparing proxy and patients' perceptions of patients' functional status: results from an outpatient geriatric clinic," Journal of the American Geriatrics Society, vol. 40, no. 6, pp. 585-588, 1992.

[41] M. MacDonald, P. Martin, J. Margrett, and L. W. Poon, "Correspondence of perceptions about centenarians' mental health," Aging and Mental Health, vol. 13, no. 6, pp. 827-837, 2009.

[42] G. G. Fillenbaum, Multidimensional Functional Assessment of Older Adults: The Duke Older Americans Resources and Services Procedures, Lawrence Erlbaum Associates, Hillsdale, NJ, USA, 1988.

[43] R. B. Tate, L. Lah, and T. E. Cuddy, "Definition of successful aging by elderly Canadian males: the Manitoba follow-up study," Gerontologist, vol. 43, no. 5, pp. 735-744, 2003.

[44] M. F. Folstein, S. E. Folstein, and P. R. McHugh, "'Mini mental state. A practical method for grading the cognitive state of patients for the clinician," Journal of Psychiatric Research, vol. 12, no. 3, pp. 189-198, 1975.

[45] O. P. Almeida, P. Norman, G. Hankey, K. Jamrozik, and L. Flicker, "Successful mental health aging: results from a longitudinal study of older Australian men," American Journal of Geriatric Psychiatry, vol. 14, no. 1, pp. 27-35, 2006.

[46] A. R. Herzog and J. S. Morgan, "Formal volunteer work among older Americans," in Achieving a Productive Aging Society, S. A. Bass, F. G. Caro, and Y. P. Chen, Eds., pp. 119-142, Auburn House, Westport, Conn, USA, 1993.

[47] A. F. Jorm, H. Christensen, A. S. Henderson, P. A. Jacomb, A. E. Korten, and A. Mackinnon, "Factors associated with successful ageing," Australasian Journal on Ageing, vol. 17, no. 1, pp. 33-37, 1998.
[48] J. Smith, Toussaint, Heuser et al., "Stress and aging: theoretical and empirical challenges for interdisciplinary research," Neurobiology of Aging, vol. 24, no. 1, pp. S77-S82, 2003.

[49] J. R. Foster, "Successful coping, adaptation and resilience in the elderly: an interpretation of epidemiologic data," Psychiatric Quarterly, vol. 68, no. 3, pp. 189-219, 1997.

[50] S. Z. Nagi, "An epidemiology of disability among adults in the United States," Milbank Memorial Fund Quarterly, Health and Society, vol. 54, no. 4, pp. 439-467, 1976.

[51] D. F. Terry, P. Sebastiani, S. L. Andersen, and T. T. Perls, "Disentangling the roles of disability and morbidity in survival to exceptional old age," Archives of Internal Medicine, vol. 168, no. 3, pp. 277-283, 2008.

[52] Y. Young, K. D. Frick, and E. A. Phelan, "Can successful aging and chronic illness coexist in the same individual? A multidimensional concept of successful aging," Journal of the American Medical Directors Association, vol. 10, no. 2, pp. 8792, 2009.

[53] U. S. Bureau of the Census, "The older population: 2010," Census Briefs, C2010BR-09, Government Printing Office, Washington, DC, USA, 2011.

[54] P. B. Baltes and J. Smith, "A systemic-wholistic view of psychological functioning in very old age: introduction to a collection of articles from the Berlin Aging Study," Psychology and Aging, vol. 12, no. 3, pp. 395-409, 1997.

[55] P. B. Baltes, "One the incomplete architecture of human ontogeny: selection, optimization, and compensation as foundation of developmental theory," American Psychologist, vol. 52, no. 4, pp. 366-380, 1997.

[56] P. B. Baltes, H. W. Resse, and J. R. Nesselroade, Life-Span Developmental Psychology: Introduction to Research Methods, Lawrence Erlbaum Associates, Hillsdale, NJ, USA, 1988.

[57] P. A. Cernin, C. Lysack, and P. A. Lichtenberg, "A comparison of self-rated and objectively measured successful aging constructs in an urban sample of African American older adults," Clinical Gerontologist, vol. 34, no. 2, pp. 89-102, 2011. 


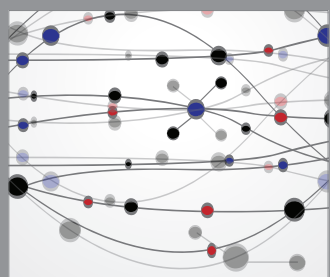

The Scientific World Journal
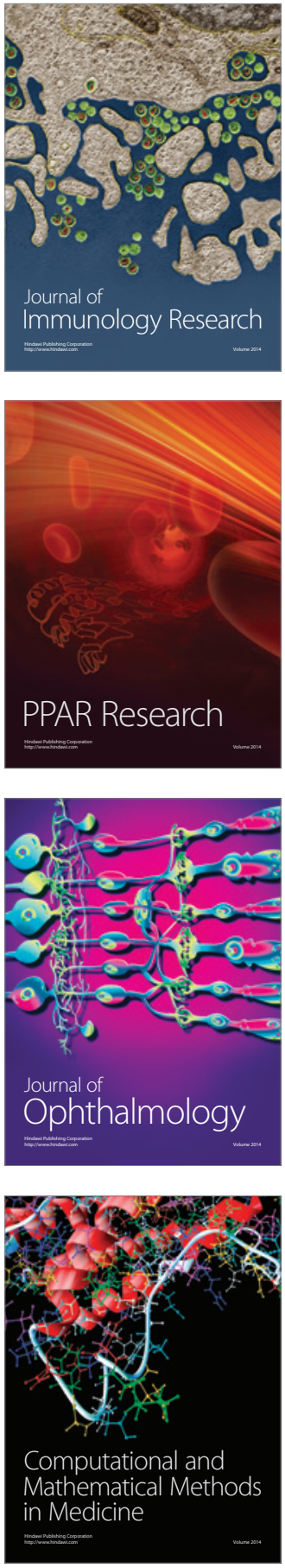

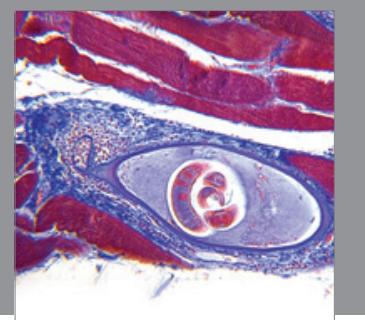

Gastroenterology

Research and Practice
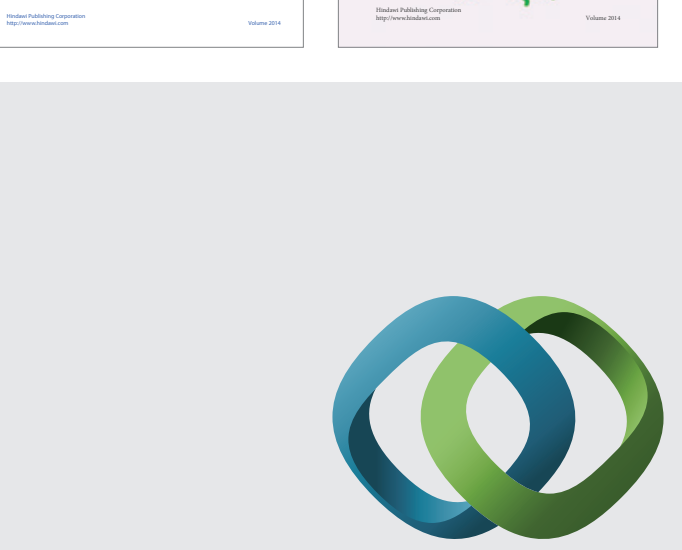

\section{Hindawi}

Submit your manuscripts at

http://www.hindawi.com
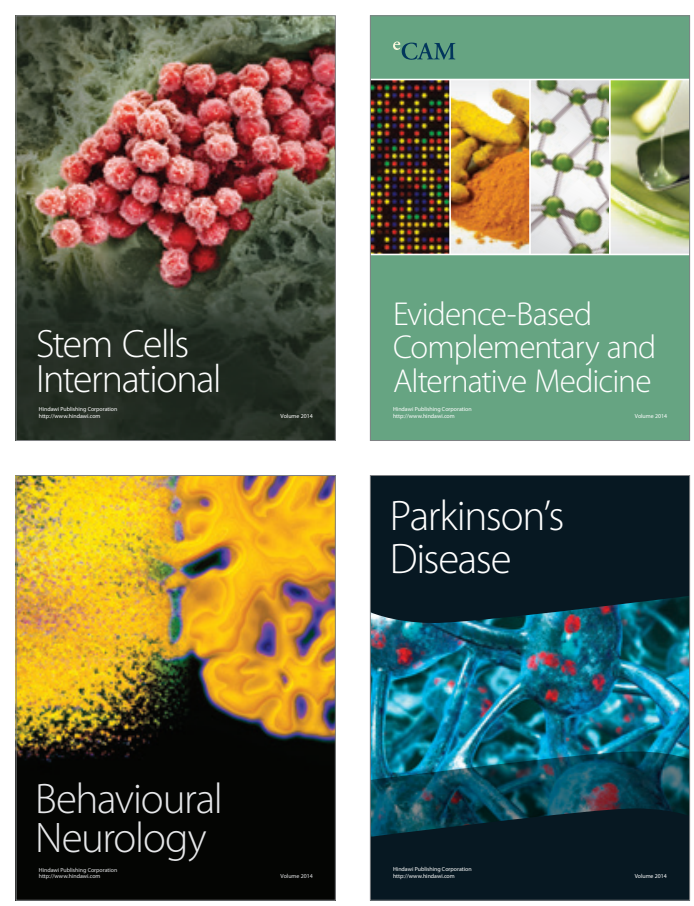

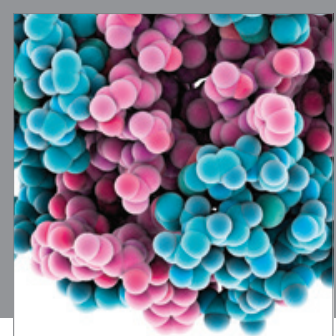

Journal of
Diabetes Research

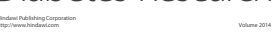

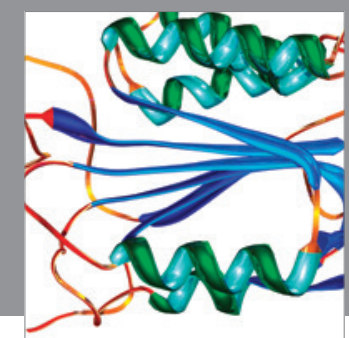

Disease Markers
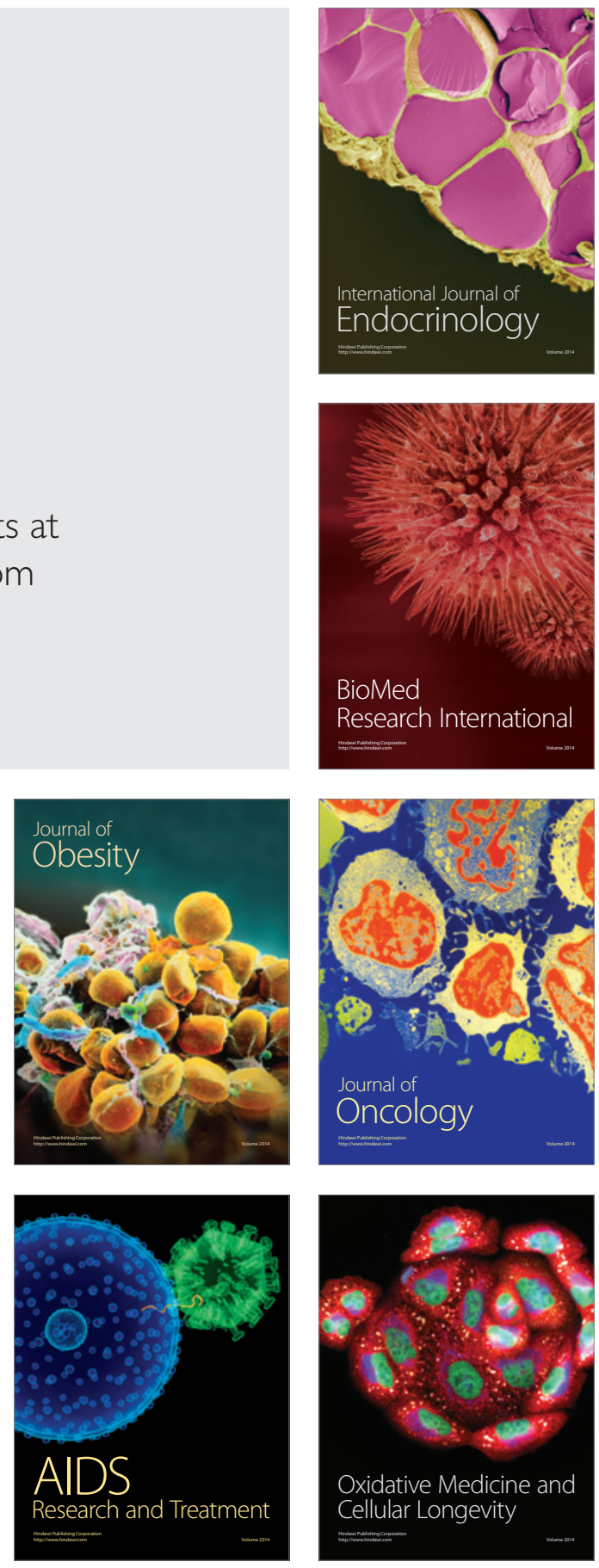